\title{
PENGEMBANGAN TEKNOLOGI GAME INDONESIA UNTUK PERMAINAN FIRST PERSON SHOOTER (FPS) 3D MULTIPLAYER “CODE TO SHOOT” MENGGUNAKAN UNITY NETWORK (UNET) BERBASIS MOBILE
}

\author{
Ibnu Ramadhan'), Agung Purwanto ${ }^{2)}$, dan Nurahman ${ }^{3)}$ \\ 1, 2,3) Jurusan Sistem Informasi, Fakultas Ilmu Komputer, UNDA University \\ Jl. Batu Berlian No. 10, Sampit - Kalimantan Tengah \\ e-mail: ibn.rmdn19@gmail.com ${ }^{1)}$, purwanto.agoeng@gmail.com ${ }^{2}$, nurrahman.ikhtiar@gmail.com ${ }^{3)}$
}

\begin{abstract}
ABSTRAK
Bermain game adalah salah satu cara untuk menghilangkan kebosanan atau menghibur diri. Saat ini sudah banyak pula variasi game yang diproduksi oleh para developer. Salah satu game yang sedang banyak berkembang dan diminati saat ini adalah FPS multiplayer dengan basis mobile. Salah satu faktor yang berpengaruh dalam hal ini adalah besarnya ketergantungan masyarakat sekarang terhadap smartphone (ponsel pintar). Namun kebanyakan game yang beredar hanya berisi hiburan semata. Atas dasar inilah penulis bermaksud untuk menyisipkan unsur budaya lokal yang akan diangkat ke dalam game tersebut yaitu budaya lokal suku Dayak Kalimantan Tengah yang penulis anggap cukup bagus untuk diangkat menjadi sebuah game multiplayer dengan menggunakan fitur Unity Network. Proses pembuatan game menggunakan bahasa pemrograman C\# serta beberapa software pendukung yaitu Unity, Blender, Visual Studio serta Android Studio untuk pembuatan game, object design dan user interface. Pada game ini juga dapat di manfaatkan sebagai penyampaian unsur budaya lokal suku Dayak Kalimantan Tengah.
\end{abstract}

Kata Kunci: Budaya Lokal, FPS Multiplayer, Game, Suku Dayak, Unity Network

\begin{abstract}
Playing a game is a way to get rid of boredom or entertain ourselves. Currently, there are many variations of games produced by developers. One of the games that are currently being developed and in demand is multiplayer FPS mobile. One of the factors that influence is the large dependence of today's society on smartphones. However, most games in circulation only contain entertainment. Base on this condition, the author intends to insert the elements of local culture that will be brought into the game, which is the local culture of the Dayak's tribe from Central Kalimantan, which I think is good enough to be made into a multiplayer game using the Unity Network feature. The process of making this game uses the C\# programming language and several supporting software, namely Unity, Blender, Visual Studio, and Android Studio, for game development, object design, and user interface. In this game, it can also be used to convey the elements of the local culture of the Dayak's tribe from Central Kalimantan.
\end{abstract}

Keywords: Dayak's Tribe, Game, Local Culture, Multiplayer FPS, Unity Network

\section{Pendahuluan}

$\mathrm{T}$ leknologi terus mengalami kemajuan dari awal kemunculannya hingga sekarang. Teknologi juga tentu saja sudah dapat dikatakan menjadi kebutuhan primer di era digital seperti sekarang. Teknologi sudah banyak digunakan masyarakat pada umunya, baik untuk tujuan kebutuhan harian, bisnis maupun hiburan. Salah satu perkembangan teknologi yang sedang booming saat ini adalah smartphone (ponsel pintar). Smartphone merupakan sebuah piranti compact di mana sebagian besar kebutuhan harian manusia akan informasi ataupun hiburan sudah terkumpul jadi satu di dalamnya. Smartphone menyediakan berbagai mobile programming yang mudah dipakai dan tentunya sangat membantu berbagai pekerjaan menjadi lebih mudah dan cepat.

Salah satu aplikasi mobile yang sering digunakan di zaman sekarang adalah game (permainan). Smartphone memiliki beragam jenis game yang disediakan, mulai dari Strategi, Balapan, RPG, FPS dan sebagainya. FPS (First Person Shooter) merupakan game yang paling banyak diminati saat ini. Hal ini terbukti dengan data dari Google Play Store di mana game jenis FPS masuk dalam jajaran 3 besar game paling populer saat ini. Selain itu, banyak developer game sekarang ini yang saling bersaing satu sama lain, menunjukkan game yang mereka buat guna memenuhi tuntutan perkembangan teknologi yang begitu cepat.

First Person Shooter merupakan sebuah permainan peperangan menggunakan senjata api dengan sudut pandang orang pertama dan hanya menampilkan senjata yang dipegang. Walaupun seperti yang sudah disinggung sebelumnya bahwa FPS masuk dalam jajaran 3 besar game yang paling diminati saat ini, kenyataannya adalah kebanyakan game jenis ini mengambil tema cerita fiksi. Sedikit sekali adanya game FPS yang memiliki tema 
kearifan lokal. Hal ini peneliti paparkan berdasarkan observasi yang peneliti lakukan dengan menginstal beberapa game FPS serta memainkannya secara langsung seperti game PUBG Mobile, CODM, Free Fire, Fortnite dan sebagainya.

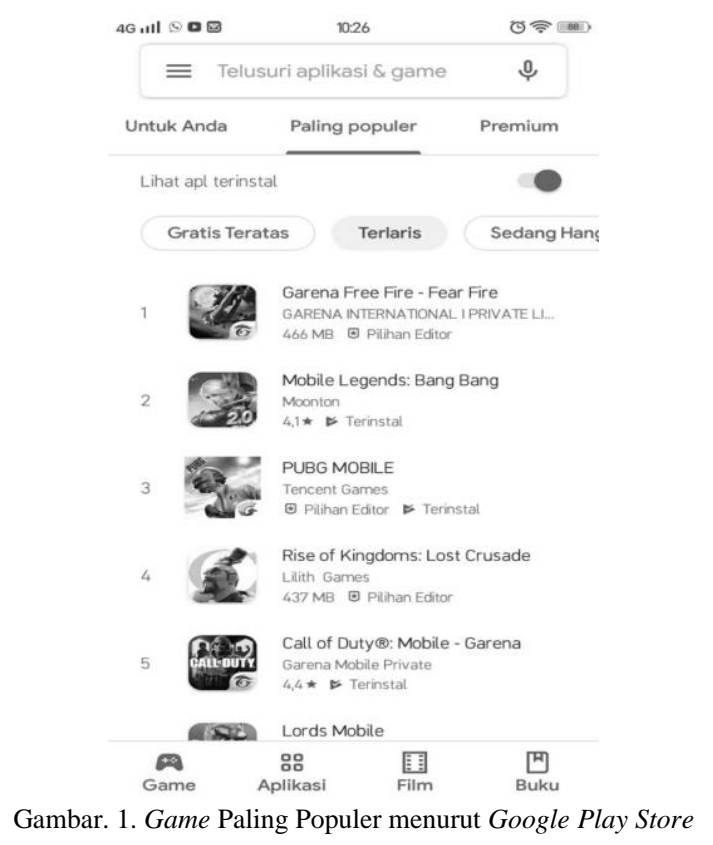

Berdasarkan permasalahan tersebut, peneliti memutuskan untuk membuat permainan jenis FPS Multiplayer dengan tema kearifan lokal terutama kearifan lokal suku Dayak Kalimantan Tengah. Salah satu contoh kearifan lokal tersebut adalah "Huma Betang" yang memiliki arti nilai kejujuran, kebersamaan, kesetaraan serta toleransi. Jika sebuah game FPS Multiplayer modern digabung dengan kearifan lokal seperti yang sudah disebutkan sebelumnya, game ini tentu saja dapat memberikan beberapa keuntungan. Pertama, karena game ini akan dibuat Multiplayer menggunakan fitur dari Unity Game Engine yaitu Unity Network, pemain tidak perlu lagi melakukan set alamat IP untuk bisa bermain game secara Multiplayer. Kedua, Game Multiplayer tentu saja akan membuat pemain bersaing secara real (nyata) dan lebih menantang di mana minimal ada 2 pemain yang akan bertemu dalam satu room. Terakhir yaitu game ini akan mengajak pemain untuk belajar tentang kearifan lokal Kalimantan Tengah sesuai dengan tema yang diterapkan.

Menurut penelitian terdahulu oleh Robert Theopani Singkoh (2016) menyatakan bahwa game selain dapat memberikan hiburan, juga dapat memberikan nilai pendidikan jika dimanfaatkan secara positif semisal penggabungan antara konsep pembelajaran (education) dan hiburan (entertainment) [1]. Sedangkan pernyataan dari Cahaya Sakti Wibowo (2015), game merupakan sebuah program yang dibuat untuk tujuan menghibur[2]. Berdasarkan beberapa hal yang sudah dipaparkan di atas yang menjadi alasan peneliti untuk membuat sebuah permainan FPS Multiplayer dengan tetap memuat kearifan lokal terutama kearifan lokal suku Dayak Kalimantan Tengah.

\section{METODOLOGI PENELITIAN}

Dalam penelitian serta penyusunan penulisan, penulis menggunakan metode-metode sebagai berikut :

\section{A. Pengumpulan Data}

1. Studi Pustaka

Peneliti mengumpulkan data dengan cara mencari referensi buku tentang penelitian terdahulu yang masih berkaitan dengan penelitian sekarang.

2. Observasi Peneliti mengumpulkan data dengan cara memainkan sekaligus mengamati secara langsung permainan sejenis yang sudah ada.

3. Wawancara

Peneliti mengumpulkan data dengan cara melakukan wawancara terhadap para gamers, terutama gamers yang memainkan permainan sejenis dengan FPS. 


\section{B. Pengembangan Sistem}

1. Analisis Data

Analisis data merupakan serangkaian kegiatan analisa terhadap data yang sudah dikumpulkan dengan tujuan untuk memberikan jawaban atas permasalahan yang sedang diteliti. Data yang sudah dikumpulkan diorganisasikan ke dalam suatu pola dan satu uraian dasar.

2. Desain Sistem

Desain sistem adalah merancang sistem baru yang diharapkan dapat membantu permasalahan pada sistem lama. Pada tahap ini masalahdigambarakan terlebih dahulu, kemudian dibuat perencanaan rancangan dari beberapa elemen yang terpisah menjadi satu kesatuan yang utuh.

3. Pembuatan Program

Tahapan pembuatan program merupakan kegiatan menerjemahkan data serta desain sistem ke dalam bahasa pemrograman tertentu agar menghasilkan aplikasi yang sesuai dengan tujuan penelitian.

4. Pengujian

Pengujian merupakan serangkaian kegiatan pengujian terhadap aplikasi yang sudah dibuat pada tahap sebelumnya.

5. Implementasi

Tahap ini merupakan tahap di mana aplikasi yang sudah dibuat dan sudah diuji coba siap untuk diterapkan.

\section{LANDASAN TEORI}

\section{A. Game Multiplayer}

Game Multiplayer merupakan sebuah game dimana biasanya terdapat dua orang atau dua tim dari para pemain untuk bersaing antara satu dengan yang lainnya di dalam permainan secara terpisah, dimana setiap pemain dapat mengontrol satu character[3].

Game Multiplayer dapat dimainkan secara masal pada waktu yang sama dan dari tempat yang berbeda. Game yang dapat dimainkan oleh banyak pemain (multiplayer) tentunya akan memberikan pengalaman bermain yang lebih menyenangkan dibandingkan jika bermain game seorang diri atau melawan AI (Artificial Intelligence)[4].

\section{B. First Person Shooter (FPS)}

First Person Shooter (FPS) adalah salah satu jenis game yang saat ini sangat digemari terutama kalangan gamers muda. FPS merupakan game yang menggunakan sudut pandang orang pertama dimana pemain akan dibuat seolaholah menjadi karakter utama dalam game dengan tampilan yang berpusat pada permainan disekitar senjata atau alat yang sedang digunakan[5].

First person shooter merupakan jenis 3D game shooter yang menampilkan sudut pandang orang pertama dengan pemain yang melihat aksi melalui mata karakter permain. Tidak seperti orang ketiga yang terlihat dari bagian belakang atau samping, yang memungkinkan gamer untuk melihat karakter secara keseluruhan[5].

FPS dikembangkan pada tahun 1973 melalui permainan ruang yang belum sempurna yaitu flight simulator, yang menampilkan sudut pandang orang pertama dengan mengarah lebih rinci ke simulator pesawat tempur, dikembangkan untuk pasukan AS pada akhir tahun 1970-an. Permainan ini tidak lagi tersedia untuk konsumen[5].

\section{Suku Dayak}

Secara umum Istilah 'Dayak' dipergunakan sebagai penyebutan bagi orang-orang asli non-Muslim, non-Melayu yang tinggal di pulau Kalimantan. Terdapat beragam penjelasan tentang etimologi istilah ini. Menurut Lindblad, kata Dayak berasal dari sebuah kah daya dari bahasa Kenyah, yang hulu [sungai] atau pedalaman. King lebih jauh menduga-duga bahwa Dayak mungkin juga dari kata saja, sebuah kata dari bahasa Melayu yang berarti asli atau pribumi. King juga yakin kata Dayak kemungkinan bersumber dari istilah bahasa daerah Jawa yang berarti perilaku 'yang pantas atau yang tak pantas[6].

Karakter lain yang menjadi bagian dari definisi orang-orang Dayak adalah praktik mereka tinggal di rumahrumah panjang bersama-sama dengan beberapa keluarga inti. Ini sudah lama menjadi fokus dalam banyak kajian (misalnya Whittier, 1978; Appell, 1978; Kedit dan Sabang, 1993; Zeppel, 1993, dll.). Organisasi sosial rumahrumah panjang di kalangan orang-orang Kenyah terdiri dari sepuluh hingga lima belas apartemen (lamin) (1987:99). Selain itu, dia menengarai bahwa tiap-tiap rumah pan-jang memiliki nama dan ketuanya sendiri, yang tinggal di lamin tengah. Lebih jauh lagi, Whit-Her memaparkan bahwa bila seorang laki-laki ingin pindah ke rumah panjang lainnya, dia harus minta izin terlebih dahulu kepada ketua rumah panjang tinggal sebelumnya. Perkawinan juga mempengaruhi pilihan orang akan rumah panjang tempatnya akan tinggal. Program-program baru pemerintah 
untuk merelokasi orang-orang Dayak tentu Saja menghancurkan organisasi sosial 'tradisional' semacam itu, karena tiap-tiap keluarga di daerah tempat tinggal yang baru masing-masing diberi rumah sendiri[6].

\section{Unity $3 D$}

Unity $3 D$ adalah sebuah game engine yang berbasis crossplatform. Unity dapat digunakan untuk membuat sebuah game yang bisa digunakan pada perangkat komputer, ponsel pintar, PS3 dan bahkan X-BOX. Unity adalah sebuah tool yang terintegrasi untuk membuat game, arsitektur bangunan dan simulasi. Unity bisa untuk game pc dan game online.[5]

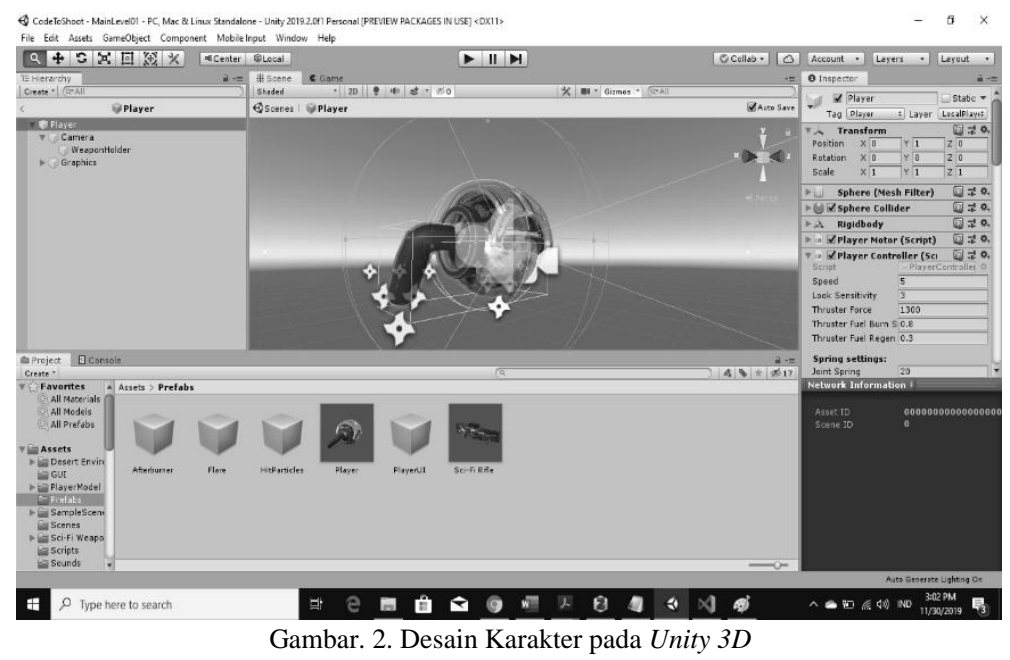

\section{E. Unity Network}

Unity Network (https://docs.unity3d.com/Manual/UNet.html) merupakan fitur yang disediakan oleh Unity untuk membuat game multiplayer. Unity Network memiliki API skrip "tingkat tinggi" (disebut sebagai HLAPI).

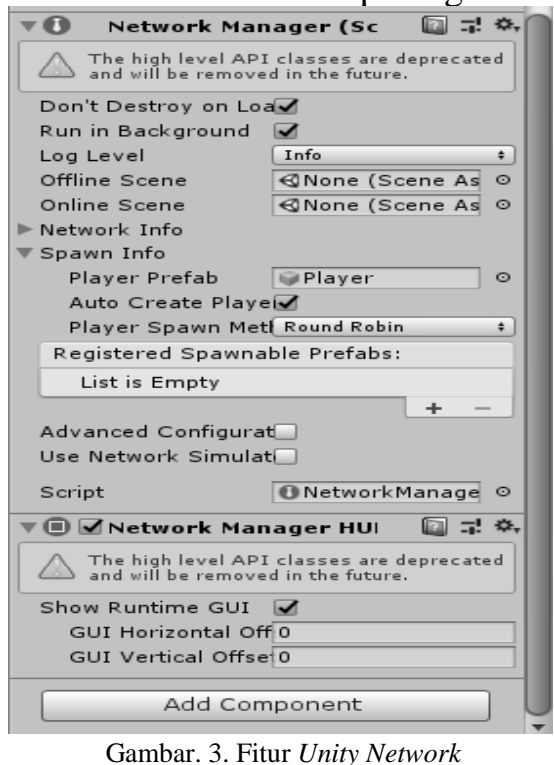

Menggunakan Unity Network berarti mendapatkan akses ke perintah yang mencakup sebagian besar persyaratan umum untuk game multiplayer tanpa perlu khawatir tentang detail implementasi "tingkat bawah". HLAPI memungkinkan untuk:

1. Kontrol keadaan jaringan dari permainan menggunakan "Network Manager."

2. Mengoperasikan game "yang dihosting klien", di mana tuan rumah juga merupakan klien pemain.

3. Serialisasi data menggunakan serializer.

4. Mengirim dan menerima pesan jaringan.

5. Mengirim perintah jaringan dari klien ke server.

6. Melakukan panggilan prosedur jarak jauh (RPC) dari server ke klien.

7. Mengirim acara berjejaring dari server ke klien. 
Ramadhan, Purwanto dan Nurahman — Pengembangan Teknologi Game Indonesia Untuk Permainan First Person Shooter (FPS) 3D Multiplayer "Code To Shoot” Menggunakan Unity Network (UNET) Berbasis Mobile

\section{HASIL DAN PEMBAHASAN}

Pada tahap ini seluruh rancangan yang sudah dihasilkan, diterjemahkan dengan mengunakan bahasa pemrograman sehingga menghasilkan sebuah sistem yang diinginkan. Dalam implementasi game fps pada penelitian ini dilakukan dengan meng-install file .apk yang ada ke smartphone. Pengujian dilakukan dengan mengunakan smartphone dengan sistem operasi Android yang kemudian akan tampil interface halaman utama.

Implementasi sistem merupakan cara menerapkan sistem dan menjalankan program aplikasi. Proses pertama saat program ini dijalankan akan tampil halaman utama di mana pada halaman ini akan muncul halaman login seperti gambar di bawah ini:

\section{A. Screenshot Layar Permainan}

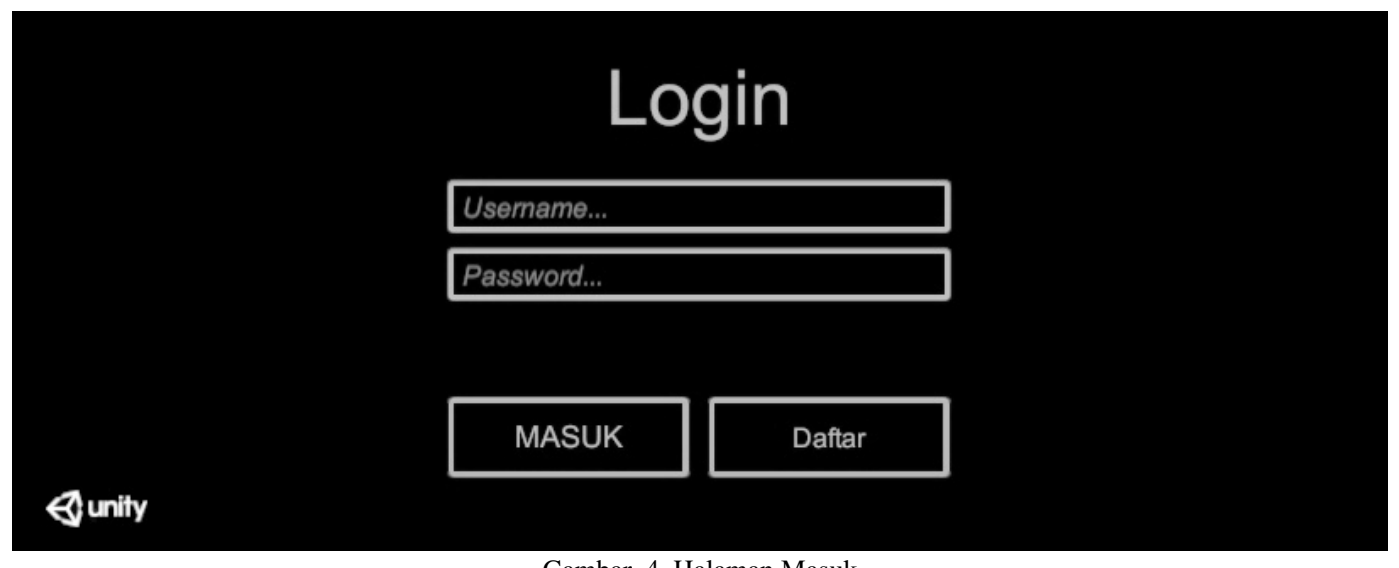

Gambar. 4. Halaman Masuk

Pada halaman ini pengguna diharuskan masuk terlebih dahulu agar bisa memainkan game "Code To Shoot". Pengguna tentu saja harus masuk menggunakan akun yang sudah terdaftar atau yang sudah mereka buat sebelumnya dengan memasukan username dan password masing-masing. Jika data akun tidak sesuai maka akan muncul pesan error. Jika data akun sudah sesuai maka pengguna akan dibawa ke halaman lobby game. Jika pengguna belum memiliki akun, pengguna baru dapat membuat akun dengan mengklik tombol register.

\section{Register}

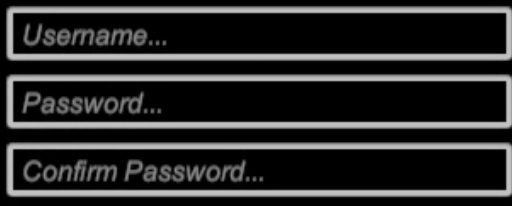

Kembali

DAFTAR

\&unity

Gambar. 5. Halaman Daftar

Halaman ini diakses hanya jika pengguna belum memiliki akun. Pengguna diharuskan membuat akun dengan memasukan beberapa data seperti username, password dan confirm password. Jika data yang dimasukan dirasa sudah benar, pengguna harus menekan tombol register dan sistem akan menyimpan data tersebut ke dalam database. Jika pengguna ingin masuk ke dalam game, pengguna tinggal mengklik tombol back dan sistem akan menampilkan halaman masuk. 


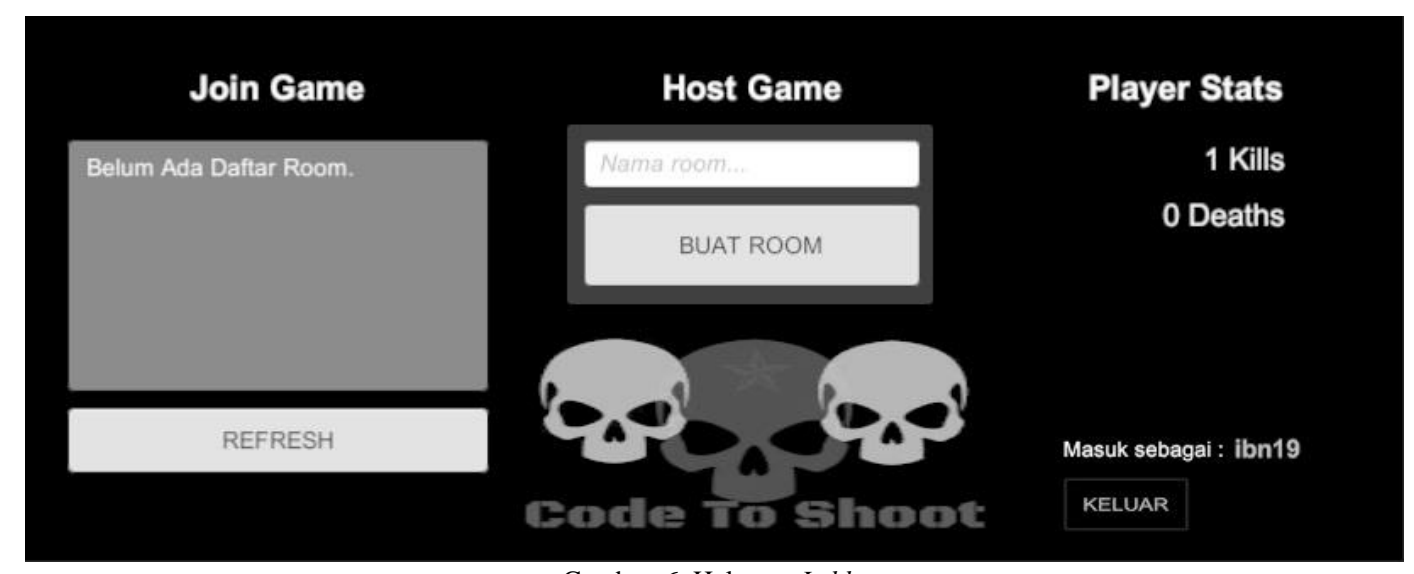

Gambar. 6. Halaman Lobby

Gambar. 6. merupakan halaman lobby game saat pengguna berhasil masuk menggunakan akun yang sudah terdaftar sebelumnya. Pada halaman ini pengguna dapat membuat room (arena bertempur) dengan cara memasukan nama room yang diinginkan, kemudian klik tombol buat room. Selain itu pengguna juga dapat melakukan join (gabung) ke dalam daftar room yang dibuat oleh pemain lain. Daftar room akan ditampilkan pada sisi kiri interface di dalam kotak daftar room. Selain itu pada halaman ini juga terdapat tombol refresh yang berfungsi untuk memuat ulang daftar room, apakah ada room terbaru yang dibuat atau tidak. Pada halaman ini juga dapat menampilkan skor permainan dari masing-masing pemain jika mereka sudah memainkan game ini sebelumnya. Skor sendiri terdiri dari berapa kali pemain dapat mengalahkan pemain lain dan berapa kali pemain tersebut dikalahkan oleh pemain lain.

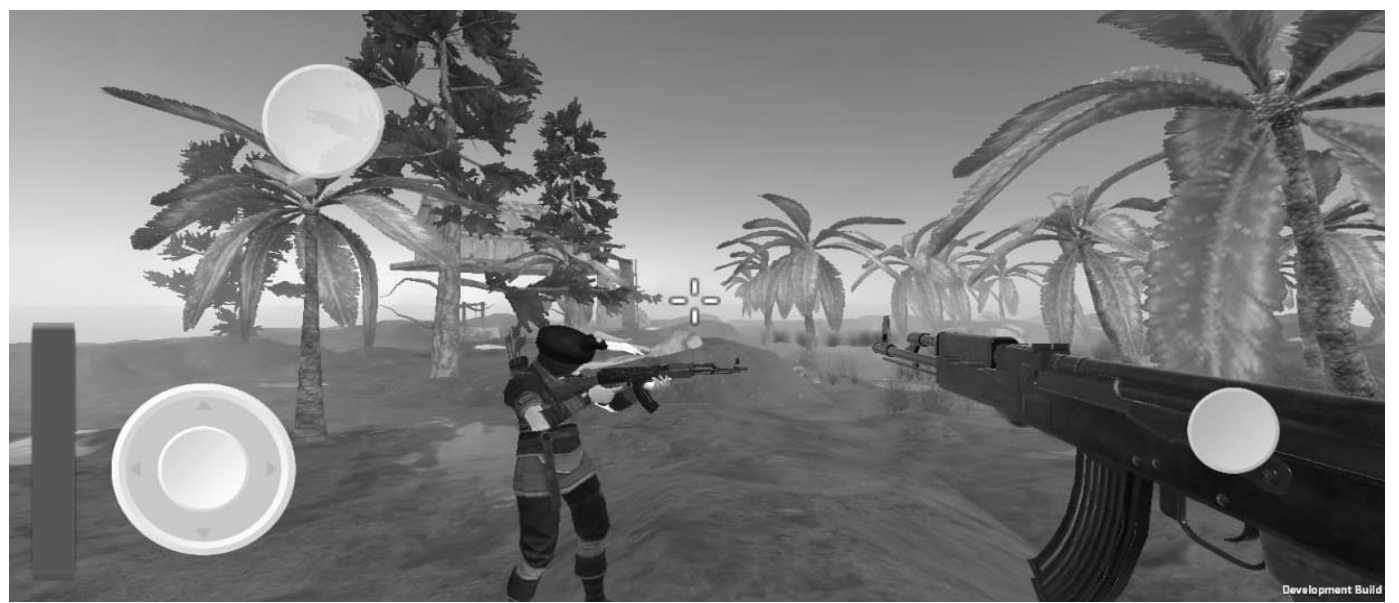

Gambar. 7. Main Level

Gambar. 7. merupakan tampilan saat dua pemain sudah berhasil masuk ke dalam room yang sudah dibuat dan siap bertempur. Saat memainkan game masing-masing pengguna dapat bergerak, melompat dan menembak. Pemain yang kalah (mati tertembak oleh pemain lain saat bermain) akan menghilang sementara dan melakukan respawn ke titik yang sudah ditentukan.

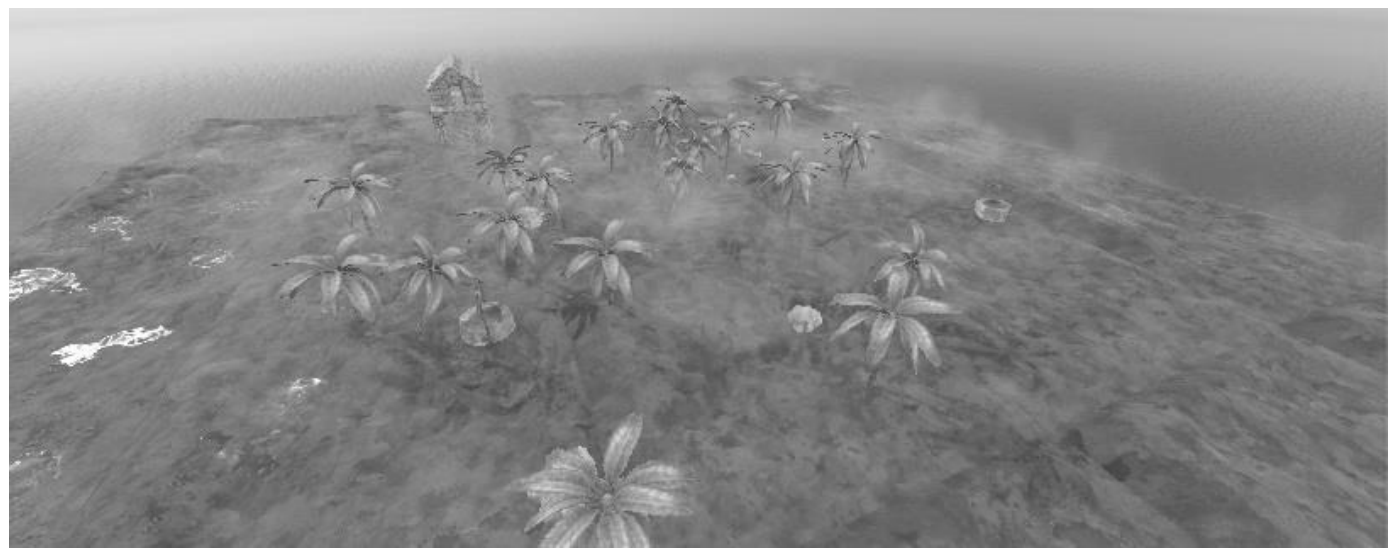

Gambar. 8. Scene Camera saat Pemain Kalah 
Ramadhan, Purwanto dan Nurahman — Pengembangan Teknologi Game Indonesia Untuk Permainan First Person Shooter (FPS) 3D Multiplayer "Code To Shoot” Menggunakan Unity Network (UNET) Berbasis Mobile

Gambar diatas merupakan contoh saat seorang pemain dikalahkan oleh pemain lainnya sebagaimana yang sudah disinggung sebelumnya. Camera dari pemain akan dinonaktifkan sementara dan object pemain akan menghilang, sedangkan scene camera akan diaktifkan sementara. Setelah itu pemain akan respawn ke titik yang sudah ditentukan dan camera pemain serta object pemain akan kembali diaktifkan.

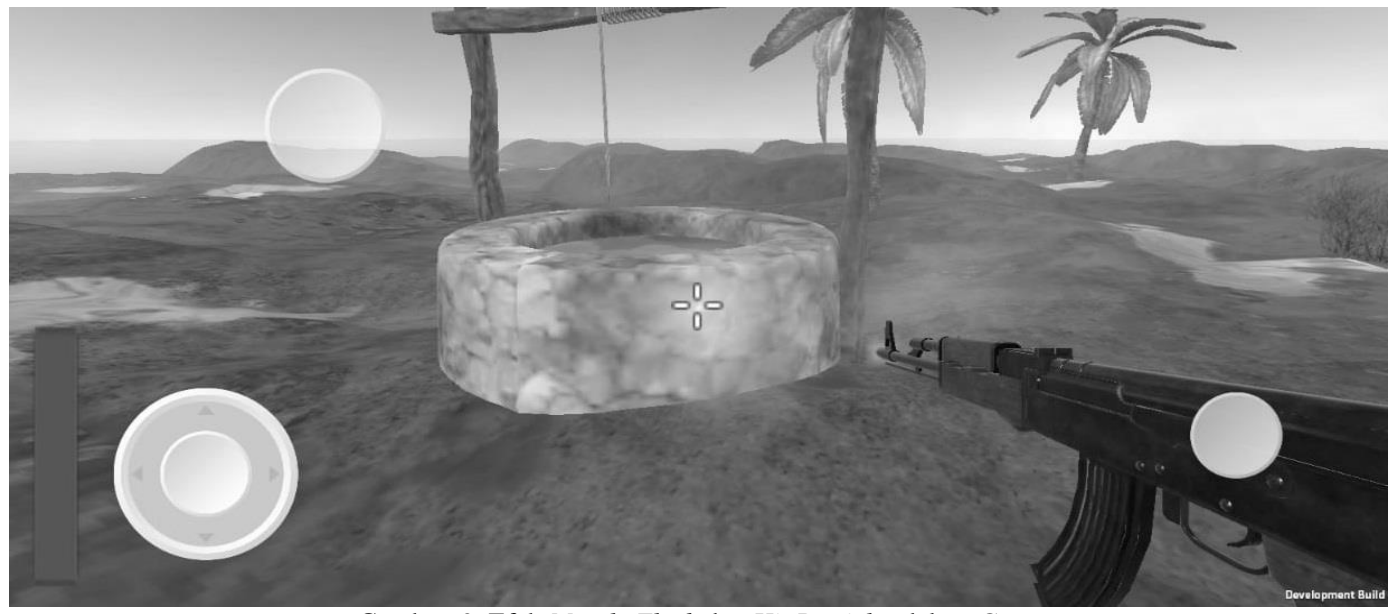

Gambar. 9. Efek Muzzle Flash dan Hit Particles dalam Game

Gambar. 9. merupakan contoh efek muzzle flash dan hit particles dalam game saat pemain menekan tombol fire (menembak).

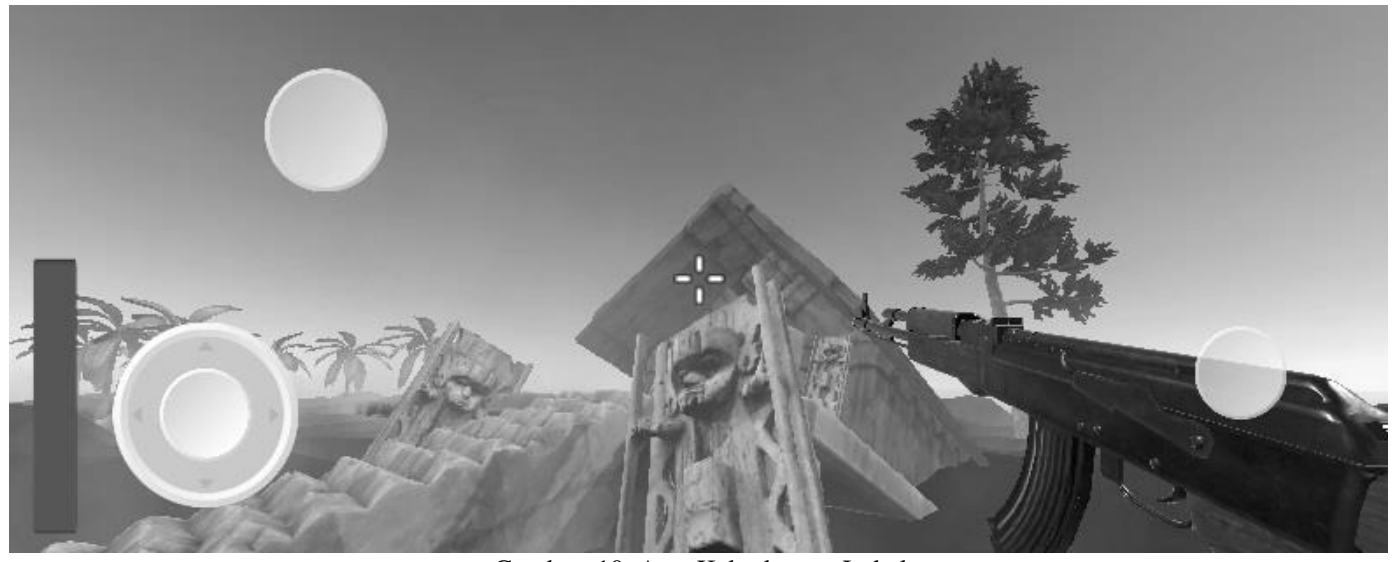

Gambar. 10. Aset Kebudayaan Lokal

Gambar diatas merupakan salah satu contoh dari beberapa aset game yang mengandung kebudayaan lokal. Pada gambar. 10. yang ditampilkan yaitu aset kebudayaan lokal berupa rumah adat serta patung adat suku Dayak di Kalimantan Tengah.

\section{B. Pengujian Sistem}

Pengujian sistem dilakukan untuk melihat apakah aplikasi yang dibuat sudah berjalan sesuai dengan yang diharapkan atau masih ada kekurangan. Penilaian terhadap pengujian aplikasi tentu saja berdasarkan pada apa yang sudah dirumuskan pada pembahasan rumusan masalah, apakah aplikasi yang sudah dibuat dan diimplementasikan sudah dapat mengatasi permasalahan yang ada secara penuh atau sebagian atau bahkan tidak sama sekali.

Di bawah ini akan dilakukan pengujian untuk game FPS Multiplayer "Code to Shoot". Pengujian pada aplikasi ini dapat dilihat pada tabel di bawah ini:

\begin{tabular}{|c|l|c|c|c|}
\hline \multicolumn{4}{|c|}{ Tabel 1. Hasil Pengujian Terhadap Akun Pengguna } \\
\hline NAME ACCOUNT & \multicolumn{1}{|c|}{ Masukan } & Keluaran & Hasil & Kesimpulan \\
\hline 1 & $\begin{array}{l}\text { Data diisi dengan } \\
\text { lengkap dan benar }\end{array}$ & Input Berhasil & Data Tersimpan ke Database & Valid \\
\hline 2 & $\begin{array}{l}\text { Data diisi dengan } \\
\text { data yang salah }\end{array}$ & Input Gagal & Data tidak tersimpan ke Database & Valid \\
\hline
\end{tabular}




\begin{tabular}{|c|l|l|l|l|}
\hline 3 & $\begin{array}{l}\text { Data tidak diisi } \\
\text { sama sekali }\end{array}$ & Input Gagal & Data tidak tersimpan ke Database & Valid \\
\hline 4 & $\begin{array}{l}\text { Mengubah data } \\
\text { akun pengguna }\end{array}$ & Null & Data tidak dapat diubah & Not Valid \\
\hline
\end{tabular}

Pada tabel 4.1. dapat dilihat bahwa dari 4 macam jenis pengujian untuk pengelolaan data akun pengguna, hanya 3 yang berhasil sedangkan 1 gagal. Pada data akun pengguna, pemain dapat menginputkan data untuk membuat akun baru maupun login ke dalam game jika sudah memiliki akun. Jika pengguna memasukan data yang salah (misalkan username pengguna sudah pernah terdaftar, salah password atau tidak memasukan data sama sekali), sistem akan memberikan feedback berupa output peringatan yang sesuai dengan kesalahannya masing-masing.

Tabel 2. Hasil Pengujian Terhadap Fitur Game

\begin{tabular}{|c|c|c|c|c|}
\hline \multicolumn{5}{|c|}{ GAME FEATURES } \\
\hline No & Masukan & Keluaran & Hasil & Kesimpulan \\
\hline 1 & $\begin{array}{l}\text { Pemain masuk } \\
\text { menggunakan akun } \\
\text { masing-masing }\end{array}$ & $\begin{array}{l}\text { Sistem menam- } \\
\text { pilkan halaman } \\
\text { lobby }\end{array}$ & $\begin{array}{l}\text { Pemain dapat melihat daftar room, } \\
\text { membuat room serta melihat status } \\
\text { pemain }\end{array}$ & Valid \\
\hline 2 & $\begin{array}{l}\text { Pemain dapat mem- } \\
\text { buat/bergabung ke } \\
\text { dalam room game }\end{array}$ & $\begin{array}{l}\text { Masuk ke main } \\
\text { level }\end{array}$ & Bermain game secara multiplayer & Valid \\
\hline 3 & $\begin{array}{l}\text { Pemain tidak perlu } \\
\text { memasukan alamat } \\
\text { IP untuk bermain } \\
\text { multiplayer }\end{array}$ & $\begin{array}{l}\text { Fitur } u N e t \text { yang } \\
\text { berfungsi } \\
\text { dengan baik }\end{array}$ & $\begin{array}{l}\text { Pemain tidak terkendala masalah jarin- } \\
\text { gan }\end{array}$ & Valid \\
\hline 4 & $\begin{array}{l}\text { Bermain game } \\
\text { dengan platform } \\
\text { mobile }\end{array}$ & $\begin{array}{l}\text { File dengan for- } \\
\text { mat .apk untuk } \\
\text { implementasi ke } \\
\text { OS Android }\end{array}$ & $\begin{array}{l}\text { Dapat dimainkan pada platform mobile } \\
\text { (Android) }\end{array}$ & Valid \\
\hline
\end{tabular}

Pada tabel 4.2. dapat dilihat bahwa pengujian untuk game mobile multiplayer semua fitur dapat berfungsi dengan baik mulai dari login ke akun masing-masing pemain, membuat/bergabung ke dalam room game, melihat daftar room yang tersedia serta fitur $u$ Net yang bekerja dengan baik sehingga pemain tidak terkendala masalah jaringan ketika memainkan game multiplayer tersebut. Selain itu game ini juga sudah dapat dimainkan pada platform mobile (Android).

Tabel 3. Hasil Pengujian Terhadap Nilai Pendidikan

\begin{tabular}{|c|c|c|c|c|}
\hline \multicolumn{5}{|c|}{ EDUCATIONAL VALUE } \\
\hline No & Masukan & Keluaran & Hasil & Kesimpulan \\
\hline 1 & $\begin{array}{l}\text { Asset game berupa } \\
\text { "Huma Betang" } \\
\text { khas suku Dayak } \\
\text { Kalimantan Tengah }\end{array}$ & $\begin{array}{l}\text { Objek pada } \\
\text { main level } \\
\text { berupa Huma } \\
\text { Betang }\end{array}$ & $\begin{array}{l}\text { Memberikan nilai pendidikan berupa } \\
\text { pengetahuan tentang rumah adat khas } \\
\text { suku Dayak }\end{array}$ & Valid \\
\hline 2 & $\begin{array}{l}\text { Asset game berupa } \\
\text { topografi yang } \\
\text { hampir mendekati } \\
\text { topografi pulau Ka- } \\
\text { limantan Tengah }\end{array}$ & $\begin{array}{l}\text { Objek pada } \\
\text { main level } \\
\text { berupa arena } \\
\text { yang hampir } \\
\text { menyerupai } \\
\text { kondisi tanah } \\
\text { Kalimantan } \\
\text { Tengah }\end{array}$ & $\begin{array}{l}\text { Memberikan nilai pendidikan berupa } \\
\text { pengetahuan tentang kondisi topografi } \\
\text { pulau Kalimantan terutama Kalteng }\end{array}$ & Valid \\
\hline 3 & $\begin{array}{l}\text { Asset game berupa } \\
\text { patung sapundu } \\
\text { khas suku Dayak }\end{array}$ & $\begin{array}{l}\text { Objek pada } \\
\text { main level } \\
\text { berupa patung } \\
\text { Sapundu khas } \\
\text { suku Dayak }\end{array}$ & $\begin{array}{l}\text { Memberikan nilai Pendidikan berupa } \\
\text { pengetahuan tentang kepercayaan } \\
\text { masyarakat Dayak secara umum serta } \\
\text { kesenian ukir khas suku Dayak Kalteng }\end{array}$ & Valid \\
\hline
\end{tabular}




\begin{tabular}{|c|c|c|c|c|}
\hline 4 & $\begin{array}{l}\text { Asset game berupa } \\
\text { backsound instru- } \\
\text { ment "Karungut" } \\
\text { lagu khas suku } \\
\text { Dayak Kalimantan } \\
\text { Tengah yang di- } \\
\text { mainkan } \\
\text { menggunakan alat } \\
\text { musik tradisional } \\
\text { yang disebut } \\
\text { "Sape" }\end{array}$ & $\begin{array}{l}\text { Objek pada } \\
\text { lobby berupa } \\
\text { musik instrumen } \\
\text { Karungut khas } \\
\text { suku Dayak Ka- } \\
\text { limantan Ten- } \\
\text { gah }\end{array}$ & $\begin{array}{l}\text { Memberikan nilai Pendidikan berupa } \\
\text { pengetahuan tentang alat musik tradi- } \\
\text { sional serta lagu daerah khas suku } \\
\text { Dayak Kalimantan Tengah }\end{array}$ & Valid \\
\hline 5 & $\begin{array}{l}\text { Asset game berupa } \\
\text { topi karakter yang } \\
\text { berbentuk kepala } \\
\text { burung "Tingang" } \\
\text { yaitu burung khas } \\
\text { Kalimantan Tengah }\end{array}$ & $\begin{array}{l}\text { Objek pada } \\
\text { main level } \\
\text { berupa topi } \\
\text { yang digunakan } \\
\text { karakter ber- } \\
\text { bentuk kepala } \\
\text { burung } \\
\text { "Tingang" }\end{array}$ & $\begin{array}{l}\text { Memberikan nilai pendidikan berupa } \\
\text { pengetahuan burung khas daerah Kali- } \\
\text { mantan Tengah }\end{array}$ & Valid \\
\hline
\end{tabular}

Pada tabel 4.3. dapat dilihat bahwa game multiplayer "Code to Shoot" dapat memberikan beberapa nilai pendidikan tentang kearifan lokal suku Dayak Kalimantan Tengah melalui beberapa asset game yang ada di dalam permainan tersebut. Nilai-nilai pendidikan tersebut diantaranya rumah adat suku Dayak, topografi tanah pulau Kalimantan Tengah, kepercayaan suku Dayak secara umum, seni ukir khas suku Dayak, musik tradisional suku Dayak dan alat musik tradisional suku Dayak serta burung khas daerah Kalimantan Tengah.

\section{KESIMPULAN}

Berdasarkan program yang sudah dibuat serta dilakukan pengujian sistem, kesimpulan yang dapat diambil dari pembuatan game FPS multiplayer "Code to Shoot" adalah sebagai berikut:

1. Game ini dapat dimainkan secara multiplayer tanpa perlu memasukan alamat IP karena fitur uNet dapat bekerja dengan baik. Selain itu game ini juga sudah dapat dimainkan menggunakan platform mobile (Android).

2. Pemain dapat melakukan pembuatan akun yang digunakan untuk login ke halaman lobby game. Saat pertama kali mendaftarkan akun, sistem dapat dengan baik melakukan pengecekan atau validasi data terkait username dan password pemain. Selain itu sistem juga dapat memberikan feedback peringatan (baik itu disebabkan salah password, username akun sudah terdaftar, password terlalu pendek, tidak ada koneksi internet serta data tidak boleh kosong).

3. Aplikasi dapat membantu pengguna untuk mengenal dan mempelajari kearifan lokal suku Dayak Kalimantan Tengah melalui aset-aset game yang dimuat di dalam permainan FPS Multiplayer "Code to Shoot". Selain itu game ini juga dapat memberikan hiburan bagi pemain yang senang bermain game FPS Multiplayer.

\section{DAFTAR PUSTAKA}

[1] R. T. Singkoh, A. S. Lumenta, and V. Tulenan, "Perancangan Game FPS (First Person Shooter) Police Personal Training," J. Tek. Elektro Dan Komput., vol. 5, no. 1, pp. 28-34, 2016 .

[2] C. Wibowo and others, "GAME MULTIPLAYER 'BALAP MOBIL' BERBASIS WEB," PhD Thesis, STMIK AKAKOM Yogyakarta, 2015.

[3] B. M. SYAIFUDIN, "PENGARUH BERMAIN VIDEO GAME TIPE MULTIPLAYER ONLINE BATTLE ARENA (MOBA) TERHADAP ATENSI," PhD Thesis, University of Muhammadiyah Malang, 2018.

[4] S. Y. Saputra and S. Subari, "Game Multiplayer 'Mini Car Circuit' Berbasis Android," J-INTECH, vol. 7, no. 01, pp. 58-66, 2019.

[5] Y. Nuruzzuha, R. Hendriyanto, and A. P. Kurniawan, "Aplikasi Game Fps" horror Of Campus"," EProceedings Appl. Sci., vol. 2, no. 3, 2016.

[6] R. Jailani and A. Purwanto, "Rancang Bangun Game 2D Dayak Run Bergenre Endles Running Berbasis Android," Inf. J. Ilm. Bid. Teknol. Inf. Dan Komun., vol. 4, no. 2, 2019. 
JTIULM - Volume 05, Nomor 2, Oktober 2020: 39 - 48 